\title{
Formulation and Characterization of Calcium- Fortified Jelly and Its Proximate Composition and Sensory Analysis
}

\author{
Naveera Younas ${ }^{1}$, Arjumand Iqbal Durrani ${ }^{1}$, Saima Rubab ${ }^{2 *}$, Aisha Munawar ${ }^{1}$, \\ Madeeha Batool ${ }^{3}$, and Asma Sheikh ${ }^{4}$ \\ ${ }^{1}$ Department of Chemistry, University of Engineering and Technology, Lahore, PAKISTAN \\ ${ }^{2}$ Department of Pharmacognosy, Lahore Pharmacy College, LMDC, Tulspura Lahore, PAKISTAN \\ ${ }^{3}$ Institute of Chemistry, University of the Punjab, New Campus, Lahore, PAKISTAN \\ ${ }^{4}$ Food and Biotechnology Research Centre, PCSIR. Labs. Complex, Lahore, PAKISTAN
}

\begin{abstract}
Calcium is a dynamic mineral. Recent discoveries designate that low intake of calcium generates deficiencies and path to other diseases. Food fortification could play a key role to overcome this problem. To cope with this deficiency problem, jellies were formulated with food-grade calcium salts and chicken eggshell powder. In the present study, three different concentrations of calcium salts, as well as eggshell powder were used to formulate jellies. The results of the sensory evaluation indicated that the two jelly products (A\&D) in the current study were suitable for consumers. Results of Atomic Absorption Spectrophotometer revealed Jelly $A$ and jelly $D$ had $151 \pm 0.05 \mathrm{ppm}$ and $133 \pm 0.06 \mathrm{ppm}$ calcium concentration, respectively. Proximate analysis of Jelly A showed that it has $6.0 \pm 0.01 \%$ ash, $9.2 \pm 0.1 \%$ moisture, $0.4 \pm 0.01 \mathrm{~g}$ crude protein, $82.79 \pm 0.001 \mathrm{~g}$ crude fiber, and $0.61 \pm 0.001 \mathrm{~g}$ crude fat, while the jelly $\mathrm{D}$ that was made with chicken eggshell powder exhibited $6.0 \pm 0.01 \%$ ash, $10.1 \pm 0.1 \%$ moisture, $0.5 \pm 0.01 \mathrm{~g}$ protein, $84.54 \pm 0.01 \mathrm{~g}$ crude fiber and $1.61 \pm 0.01 \mathrm{~g}$ crude fat. Therefore, these two jelly $A \& \mathrm{D}$ were greatly appreciated among other attributes. In spite of naturally available calcium-rich sources, calcium-fortified jellies can be consumed by individuals who are incapable to take sufficient calcium from their diet.
\end{abstract}

Key words: food formulation, calcium-fortified jellies, gelatin, proximate, sensory evaluation, brix value, refractive index

\section{Introduction}

Calcium is an essential element as it is the richest inorganic element in the human body, accounting for $1-2 \%$ of the body mass ${ }^{1)}$. About $99 \%$ of the body's calcium is in bones and teeth giving a negotiable pool of calcium ${ }^{2}$. The leftover $1 \%$ is circulating in fluids and is liable for the ruling of metabolic functions like hormone discharge, blood coagulation, normal heart rate, enzyme activation, and cell membrane maintenance ${ }^{3)}$. Low intake or absorption of mineral-like calcium might generate deficiencies which in turn are related to many human health problems. Calcium deficiency is often connected with vitamin D deficiency, which leads to complications with bone mineralization and severe muscle cramps $^{4)}$.

Two forms of calcium deficiency are mostly found in humans, i.e., dietary calcium deficiency and hypocalcemia. Dietary calcium deficiency is related to insufficient calcium consumption that can cause osteoporosis. There should be sufficient calcium in the diet of children before adulthood so that the bones are well firmed and adults do not develop osteoporosis $^{5)}$. Hypocalcemia is a condition in which there is a low calcium level in blood ${ }^{6)}$. Hypocalcemia can present as an asymptomatic condition, or as a severe, life-threatening condition. This deficiency may be due to a variety of factors, including poor calcium intake over a while, treatments that may decrease calcium absorbance, dietary intolerance to foods rich in calcium, and many genetic factors also ${ }^{7)}$.

Food fortification could play a key role to overcome this deficiency problem. Milk and other dairy food items such as yogurt, mozzarella \& cheese, etc. are acknowledged as an ideal source of calcium in diet ${ }^{8)}$. There are calcium choices of nondairy products such as broccoli, spinach, sesame seed, \& almonds for those who do not consume \footnotetext{
Dental College, Tulspura Lahore, PAKISTAN

E-mail: saima.rubab @Imdc.edu.pk ORCID ID: https://orcid.org/0000-0003-1502-6425

ORCID ID: Naveera Younas (https://orcid.org/0000-0001-7328-9130), Arjumand lqbal Durrani (https://orcid. org/0000-0002-3754-3135), Aisha Munawar (https://orcid.org/0000-0002-0135-9985), Madeeha Batool (https://orcid.org/0000-0002-1325-1998), Asma Sheikh (https://orcid.org/0000-0002-5632-785X/print) Accepted February 17, 2021 (received for review February 3, 2021) Journal of Oleo Science ISSN 1345-8957 print / ISSN 1347-3352 online http://www.jstage.jst.go.jp/browse/jos/ http://mc.manusriptcentral.com/jjocs
}

*Correspondence to: Saima Rubab, Department of Pharmacognosy, Lahore Pharmacy College, A Project of Lahore Medical and

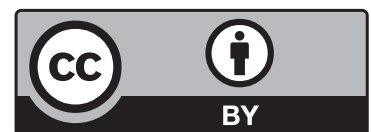


dairy products. Despite these naturally available calciumrich sources, fortified foods are a very useful mode of helping those individuals who are incapable to consume satisfactory calcium from alimentary sources. From this perspective, food fortification is a good alternative approach $^{9)}$. Food fortification is proven a cost-effective and high-impact solution to micronutrients deficiencies. Staple food can be fortified with micronutrient, including iron, calcium, magnesium, folic acid, vitamin A, iodine, and others, without affecting taste and color ${ }^{10)}$.

Several studies about the fortification of food with minerals have been published in recent years. Jelly was chosen for fortification because of its tempting nature and extensive consumption among children. A few countries added calcium to flour, but it is more usually added to other food. Calcium salts (Calcium carbonate, Calcium gluconate)were used to fortify the jellies ${ }^{11)}$. On the other hand, the chicken eggshell powder was also used to fortify the jellies. Both types of jellies were formed to check their properties after preparation and during storage time too. In the end, the results were compared with each other to select the jelly with good perception. Food grade salts were used for jelly fortification.

Hidden hunger ${ }^{12)}$ that is, the second name of micronutrient malnutrition ${ }^{13)}$, is affecting most countries of Central and South Asia ${ }^{14)}$. The main objective behind the formulation of this fortified jelly was to produce food that can be a vehicle to provide sufficient levels of calcium and help offset this deficiency problem among the local population. Ending hunger regarding calcium is the aim of this research. This product will also help to understand the benefits of fortification later and more working on this idea will help to produce a high-quality calcium-fortified jelly.

\section{Materials and Methods}

Food-grade calcium salts, i.e., calcium carbonate, calcium gluconate, and brown chicken eggshells, were used for fortification. Calcium salts, brown chicken eggshells, and other ingredients (gelatin, sugar, and citric acid)were obtained from a local market in Lahore. Food flavor and color additives were purchased from Abkari market, Lahore. For the determination of mineral $(\mathrm{Ca})$, aqua regia was utilized for the digestion of samples that were prepared in the laboratory. For crude protein determination, digestion mixture $\left(\mathrm{CuSO}_{4}: \mathrm{K}_{2} \mathrm{SO}_{4}\right)$ was also being used in a $1: 8$ ratio.

\subsection{Preparation of calcium-fortified jelly with calcium salt}

Calcium-fortified jellies were prepared with three different concentrations of calcium salts. In this formation of calcium-fortified jellies, distilled water was used and brought to the boiling ${ }^{15)}$. The mixture containing salts, gelatin, sugar, and citric acid was added in boiling water and stirred well for 3-4 minutes with a medium flame. Finally, food flavor and color were added as per taste ${ }^{16)}$. Then the mixture solution was poured into a jelly mold and cooled at ambient temperature and stored in sterilized boxes ${ }^{17)}$. The basic Formulations of calcium-fortified jellies are shown in Table 1. All three jelly formulations were subjected to sensory analysis and proximate analysis ${ }^{18)}$.

\subsection{Preparation of eggshell powder}

The eggshell powder was formed by passing the brown chicken eggshells through three stages, i.e., washing, boiling, and drying. Eggshells were thoroughly washed twice under running tap water for the elimination of any infectious agent presence ${ }^{19)}$. Then, the eggshells were boiled for 20 minutes to inactive any microbial contamination $^{20)}$. After boiling, the eggshells were dried in an oven and grounded in mortar \& pestle to form a coarse powder $^{21)}$.

\subsection{Preparation of calcium-fortified jelly with chicken egg- shell powder}

Three different concentrations of brown chicken eggshell powder were used in the production of jellies. In the preparation of these jellies, the same above stated method was applied. The distilled water was brought to boiling, after that mixture of eggshell powder, gelatin, sugar, and citric acid was added in the boiling water and stirred for about

Table 1 Formulations of Calcium-fortified jellies.

\begin{tabular}{|c|c|c|c|c|c|c|c|}
\hline $\begin{array}{l}\text { Sample } \\
\text { code }\end{array}$ & $\begin{array}{l}\text { Brown chicken } \\
\text { eggshell powder } \\
(\mathrm{g})\end{array}$ & $\begin{array}{l}\text { Calcium } \\
\text { carbonate } \\
(\mathrm{g})\end{array}$ & $\begin{array}{l}\text { Calcium } \\
\text { gluconate } \\
(\mathrm{g})\end{array}$ & $\begin{array}{c}\text { Gelatin } \\
\text { (g) }\end{array}$ & $\begin{array}{l}\text { Sugar } \\
(\mathrm{g})\end{array}$ & $\begin{array}{c}\text { Citric acid } \\
\text { (g) }\end{array}$ & $\begin{array}{c}\text { Water } \\
(\mathrm{ml})\end{array}$ \\
\hline A & - & 0.3 & 0.24 & 25 & 50 & 0.5 & 300 \\
\hline $\mathrm{B}$ & - & 0.35 & 0.27 & 25 & 50 & 0.5 & 300 \\
\hline $\mathrm{C}$ & - & 0.43 & 0.4 & 25 & 50 & 0.5 & 300 \\
\hline $\mathrm{D}$ & 0.3 & - & - & 25 & 50 & 0.5 & 300 \\
\hline $\mathrm{E}$ & 0.36 & - & - & 25 & 50 & 0.5 & 300 \\
\hline $\mathrm{F}$ & 0.5 & - & - & 25 & 50 & 0.5 & 300 \\
\hline
\end{tabular}




\section{Formulation and Characterization of Calcium-Fortified Jelly}

3-4 minutes. At the end flavor and color was added in it. The only difference in the method was the use of chicken eggshell powder instead of calcium salts. Jellies made from chicken eggshell powder are named D, E \& F.

\subsection{Chemical analysis of calcium-fortified jelly}

\subsubsection{Proximate composition}

The chemical analysis including moisture, ash, fat, protein, and fiber were performed on these jellies. The moisture \& ash content, crude fat, crude protein $(\mathrm{N} \times$ $6.25)$, \& crude fiber were determined according to AOAC (2005) methods ${ }^{22)}$. All measurements were carried out in triplicate. The mean score of the results was reported.

2.4.1.1 pH and acidity

All fortified jelly samples were analyzed by using standard analytical methods. $\mathrm{pH}$ is an indication of the acidity of the solution. The $\mathrm{pH}$ value of 5-6 is considered optimal for gelling and taste reasons. The $\mathrm{pH}$ of the prepared jellies was measured by using a digital $\mathrm{pH}$ meter at room temperature $\left(25^{\circ} \mathrm{C} \pm 5^{\circ} \mathrm{C}\right)$. For this purpose, $0.5 \mathrm{~g}$ of jelly was dispersed in $50 \mathrm{~mL}$ of distilled water to make a $1 \%$ solution, and then $\mathrm{pH}$ was noted ${ }^{23)}$. The acid-base titration method was also used to calculate the acidity of jelly samples.

\subsubsection{Brix value and refractive index}

A refractometer was used to check the refractive index and Brix value of jelly samples. Brix is the sugar concentration in the product. Measurements should be made at $20^{\circ} \mathrm{C}$ to get an accurate value.

\subsubsection{Mineral $(\mathrm{Ca})$ determination}

All the fortified jellies were analyzed after preparation. Several methods are available for mineral content determination $^{24)}$. In the present study, the mineral content of jelly was determined by Atomic Absorption Spectrometry according to the standard methods. jellies samples ( $5 \mathrm{~g})$ were digested in aqua regia $\left(\mathrm{HCl}: \mathrm{HNO}_{3}, 3: 1\right)$ by heating and then diluted with double distilled water (up to $25 \mathrm{ml}$ ). After digestion and filtration, mineral (Ca)was determined using Atomic Absorption Spectrophotometer (AAS). The filtered solution was vaporized and atomized in the flame. The atoms then absorbed the light at a characteristic wavelength. The source of the light was a hollow cathode lamp, which was made up of the same element to be analyzed. The lamp produced radiation of a suitable wavelength between 190 and $320 \mathrm{~nm}$, which while passing through the flame was absorbed by the free atoms of the sample. The absorbed energy was measured by a photodetector readout system. The amount of energy absorbed is proportionate to the concentration of the element in sample ${ }^{25)}$.

2.4.2 Sensory evaluation

To determine the acceptance of fortified jellies with calcium salts and eggshell powder, a sensorial evaluation of all six samples was carried out by five semitrained panelists. Three samples of jelly with calcium salts and the other three with eggshell powder were evaluated. Jelly produced from a ready-made gelatin mixture was used as a control. Sensory evaluation was based on a simple hedonic scale of five points, 1 = extremely disliked to 5 =extremely liked. The evaluation was based on five attributes: appearance, taste, aroma, color, \& overall acceptability ${ }^{26)}$.

\section{Results and Discussion}

\subsection{Proximate composition of calcium-fortified jellies}

The proximate content ${ }^{27)}$ of calcium-fortified jelly samples is presented in Table 2. There was no difference in ash content of both samples (A \& D). Both best attributes share the same ash content of $6.0 \pm 0.01 \%$ ash. A slight increase was observed in the moisture content of sample D $10.1 \pm 0.1 \%$ ) (fortified with eggshell powder) compared to sample A $(9.2 \pm 0.1 \%)$ i.e., fortified with calcium salts. The decrease in moisture content of Jelly A as compared to Jelly D suggests that the reduction in the moisture content would interrupt the proliferation of micro-organisms ${ }^{28)}$. However, the crude fat content of jelly D increased and differed significantly with the addition of eggshell powder. Jelly A had a low crude fat content $0.61 \pm 0.001 \mathrm{~g}$ and jelly $\mathrm{D}$ had a high-fat content $1.61 \pm 0.01 \mathrm{~g}$. Similarly, the crude fiber content increased with the addition of eggshell powder in jelly D $84.54 \pm 0.01 \mathrm{~g}$. While jelly A had less crude fibers $82.79 \pm 0.01 \mathrm{~g}$ compared to jelly D. This observation indicates that the sample with low dietary fiber (jelly A) will digest easily and will promote good health ${ }^{29)}$. There was no significant difference in the protein content of jelly $\mathrm{A}(0.4 \pm 0.01 \mathrm{~g})$ and Jelly D $(0.5 \pm 0.01 \mathrm{~g})$.

\section{$3.1 .1 \mathrm{pH}$ and acidity of jellies}

The $\mathrm{pH}$ of the jelly samples was found out to be between the optimum range of 4.5-5.0. In foods, acidity indicates the content of free acids and other chemical compounds. The acid-base titration method indicated that the acidity of both jelly samples was in the acceptable range of $0.1 \pm$ $0.006 \%$ and $0.13 \pm 5.7 \% \mathrm{pH}$ and acidity are important pa-

Table 2 Proximate \& chemical analysis of Calcium-fortified jellies.

\begin{tabular}{lcc}
\hline \multicolumn{1}{c}{ Nutrient } & Jelly A $(100 \mathrm{~g})$ & Jelly D (100g) \\
\hline $\mathrm{pH}$ & $4.5 \pm 0.05$ & $4.5 \pm 0.05$ \\
Acidity & $0.1 \pm 0.01 \%$ & $0.13 \pm 5.7 \%$ \\
Refractive Index (RI) & $1.392 \pm 0.1 \mathrm{nD}$ & $1.3847 \pm 0.1 \mathrm{nD}$ \\
Degrees Brix & $36.0 \pm 0.1 \%$ & $33.0 \pm 0.05 \%$ \\
Ash & $6.0 \pm 0.01 \%$ & $6.0 \pm 0.01 \%$ \\
Moisture & $9.2 \pm 0.1 \%$ & $10.1 \pm 0.1 \%$ \\
Crude protein & $0.4 \pm 0.01 \mathrm{~g}$ & $0.5 \pm 0.01 \mathrm{~g}$ \\
Crude fiber & $82.79 \pm 0.001 \mathrm{~g}$ & $84.54 \pm 0.01 \mathrm{~g}$ \\
Crude fat & $0.61 \pm 0.001 \mathrm{~g}$ & $1.61 \pm 0.01 \mathrm{~g}$ \\
\hline
\end{tabular}


Table 3 Mineral content of fortified jellies.

\begin{tabular}{cc}
\hline Sample code & Calcium $(\mathrm{ppm})$ \\
\hline A & $151 \pm 0.05$ \\
B & $173 \pm 0.05$ \\
C & $226 \pm 0.06$ \\
D & $133 \pm 0.06$ \\
E & $150 \pm 0.057$ \\
F & $170 \pm 0.05$ \\
\hline
\end{tabular}

rameters to assess the internal quality of the processed jellies for their potential use ${ }^{30)}$.

Results of $\mathrm{pH}$ and acidity are given in Table 2. The overall results of $\mathrm{pH}$ and acidity for the samples showed no significant differences because the fortified jellies have the same behavior as other simple jellies.

3.1.2 Degrees Brix and refractive index

The refractive index and degree Brix were measured by using a refractometer. Measurement was made at $20^{\circ} \mathrm{C}$ to get an accurate value of Brix ${ }^{31)}$. Degree Brix for any jelly item should be 40 . The fortified jellies were near to this value. Sample A has a degree Brix of $36 \pm 0.1 \%$ and sample D has $33 \pm 0.005 \%^{32)}$.

3.1.3 Mineral content of calcium-fortified jellies

The mineral content of the jelly samples was presented in Table 3. The mineral content of jellies fortified with a higher concentration of calcium salts and eggshell powder had significantly higher calcium content ${ }^{33)}$. While samples with a low concentration of salts and eggshell powder have lower calcium content ${ }^{34)}$. In all these samples, sample A and sample D had calcium content in a limited range that can be given in any fortified food. Jelly A and Jelly D have 151 ppm and 133 ppm respectively. While jelly $\mathrm{C}$ had the highest amount of calcium content (226 ppm) among the jellies that formulated with calcium salts. While jelly $\mathrm{F}$ had the highest amount of calcium (170 ppm)among other samples of eggshell powder ${ }^{35)}$.

\subsection{Sensory evaluation of calcium-fortified jellies}

The results of the sensory evaluation are summarised in Figs. 1 and 2 for jelly A and jelly D, respectively. The results showed that there was no significant difference in color and appearance of all fortified samples ${ }^{36)}$. The rating for aroma showed that panelists placed preference to the sample with the least amount of salt and eggshell powder. Ratings for taste showed a slight difference among the samples $^{37)}$. Samples with less amount of salt and powder were preferred by the panelists. The scores of almost all the sensory attributes of fortified jellies were not different from each other(Fig. 1). The jelly samples with a higher concentration of calcium salts and the eggshell powder were bitter and crunchy in taste compared to other samples with low calcium concentration(Fig. 2). In all, the

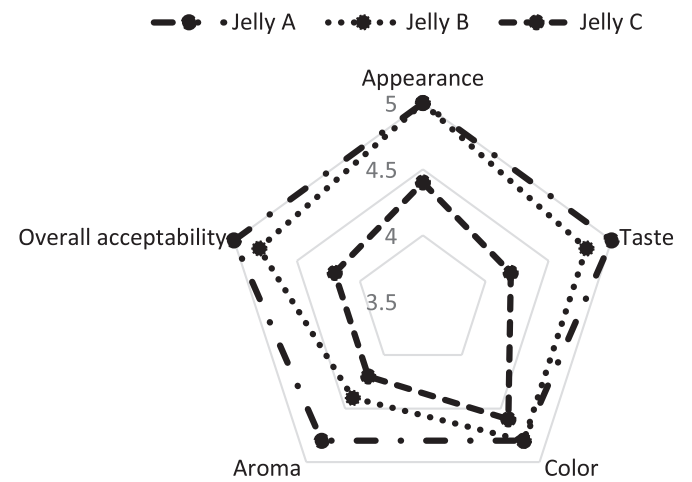

Fig. 1 Sensory evaluation chart of calcium-fortified jelly A.

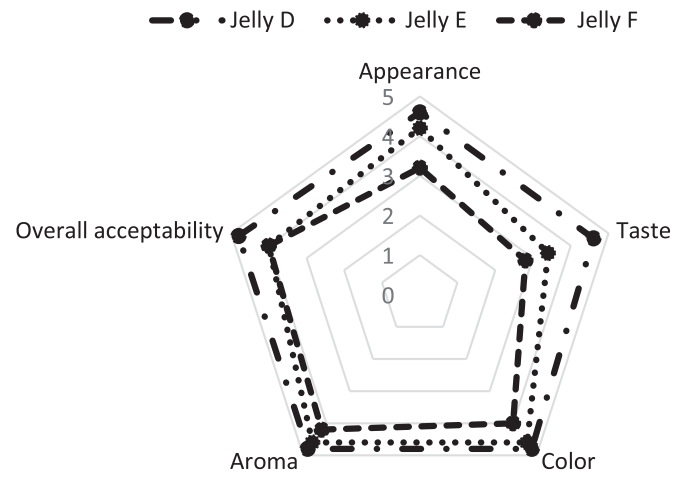

Fig. 2 Sensory evaluation chart of calcium-fortified jelly D.

result of overall acceptability revealed that jelly A and jelly D had the best rating ${ }^{38)}$.

\section{Conclusion}

It can be concluded from the present findings that the better quality of calcium-fortified jelly can be prepared by using calcium carbonate $(0.3 \mathrm{~g})$ and calcium gluconate $(0.24$ g) along with $50 \mathrm{~g}$ sugar and $25 \mathrm{~g}$ gelatin. Jelly sample A was far better than sample B \& C in chemical analysis and sensory evaluation. Chicken eggshell calcium-fortified jelly sample D was of better quality among the other two eggshell samples with $0.3 \mathrm{~g}$ of eggshell powder. This enriched food was prepared for consumption by humans to fulfill their daily calcium needs. To determine the effect and differences between jellies fortified with calcium salts and fortified with eggshell powder, different analysis techniques were carried out. Fortification resulted in increased proximate and mineral content of fortified jellies. In general terms, the fortified samples were sensory well accepted, it was witnessed that the best scores were achieved by sample A and sample D of all aspects. This study shows that fortification could be of great advantage to developing countries, where many cannot afford highly enriched foods because of their cost. This food could help them in reducing calcium deficiencies. 


\section{Conflict of Interest}

The authors declare no conflict of interest.

\section{Acknowledgement}

The authors would like to express their sincere thanks to Chemistry Department, UET. Pakistan.

\section{References}

1) Vannucci, L.; Fossi, C.; Quattrini, S.; Guasti, L.; Pampaloni, B.; Gronchi, G.; Brandi, M.L. Calcium intake in bone health: a focus on calcium-rich mineral waters. Nutrients 10, 1930 (2018).

2) Raskh, S. The importance and role of calcium on the growth and development of children and its complications. Int. J. Res. Appl. Sci. Biotechnol. 7, 162-167 (2020).

3) Reid, I.R.; Bristow, S.M.; Bolland, M.J. Calcium supplements: Benefits and risks. J. Intern. Med. 278, 354368 (2015).

4) Pravina, P.; Sayaji, D.; Avinash, M. Calcium and its role in human body. Int. J. Pharm. Biomed. Sci. 4, 659668(2013).

5) Tu, K.N.; Lie, J.D.; Wan, C.K.V.; Cameron, M.; Austel, A.G.; Nguyen, J.K.; Hyun, D. Osteoporosis: A review of treatment options. Pharm. Ther. 43, 92 (2018).

6) Liu, J.; Han, P.; Wu, J.; Gong, J.; Tian, D. Prevalence and predictive value of hypocalcemia in severe COVID-19 patients. J. Infect. Public Health 13, 1224-1228 (2020).

7) Schafer, A.L.; Shoback, D.M. Hypocalcemia: Diagnosis and treatment. MDText.com, Inc., South Dartmouth (2015).

8) O'neil, C.; Keast, D.; Fulgoni, V.; Nicklas, T. Food sources of energy and nutrients among adults in the US 2003-2006. Nutrients 4, 2097-2120 (2012).

9) Datta, M.; Vitolins, M.Z. Food fortification and supplement use are there health implications? Crit. Rev. Food Sci. Nutr. 56, 2149-2159 (2016).

10) Maurya, V.K.; Bashir, K.; Aggarwal, M. Vitamin D microencapsulation and fortification: Trends and technologies. J. Steroid Biochem. Mol. Bio. 196, 105489 (2020).

11) Palacios, C.; Hofmeyr, G.J.; Cormick, G.; Garcia-Casal, M.N.; Peña-Rosas, J.P.; Betrán, A.P. Current calcium fortification experiences: A review. Ann. N. Y. Acad. Sci. 1484, 55-73(2020).

12) Neff, L.M. Hidden hunger: Food insecurity in the age of coronavirus. Am. J. Clin. Nutr. 112, 1160-1161 (2020).

13) Murray, R.D.; Kerr, K.W.; Brunton, C.; Williams, J.A.;
DeWitt, T.; Wulf, K.L. A first step towards eliminating malnutrition: a proposal for universal nutrition screening in pediatric practice. Nutr. Diet Suppl. 13, 17-24 (2021).

14) Tam, E.; Keats, E.C.; Rind, F.; Das, J.K. Micronutrient supplementation and fortification interventions on health and development outcomes among children under five in low-and middle-income countries: A systematic review and meta analysis. Nutrients 12, 289 (2020).

15) Athaillah, Z.A.; Eviana, I.; Pudjiraharti, S.; Haryono, A. Optimization of carrageenan-based jelly products added with nutrients for reducing osteoporosis risks. AIP Conf. Proc. 1904, 020051 (2017).

16) Lee, E.H.; Yeom, H.J.; Ha, M.S.; Bae, D.H. Development of banana peel jelly and its antioxidant and textural properties. Food Sci. Biotechnol. 19, 449-455 (2010).

17) Panchal, J.B.; Gaikwad, R.S.; Dhemre, J.K.; Chavan, U.D. Studies on preparation and storage of jelly from dragon fruit(Hylocereus undatus). J. Pharmacogn. Phytochem. 7, 2648-2655 (2018).

18) Takeungwongtrakul, S.; Thavarang, P.; Sai-Ut, S. Development of strawberry gummy jelly with reduced sugar content from strawberry syrup. Int. J. Agric. Tech. 16, 1267-1276 (2020).

19) Siddique, S.; Firdous, S.; Durrani, A.I.; Khan, S.J.; Saeed, A. Hesperidin, a citrus flavonoid, increases the bioavailability of micronutrients of Gallus domesticus (chicken) eggshell: in vitro study. Chem. Speciat. Bioavailab. 28, 88-94 (2016).

20) El-Shibiny, S.; El-Gawad, M.A.E.K.; Abd, M.; Assem, F.M.; El-Sayed, S.M. The use of nano-sized eggshell powder for calcium fortification of cow's and buffalo's milk yogurts. Acta Sci. Pol. Technol. Aliment. 17, 37-49 (2018).

21) Ray, S.; Barman, A.K.; Roy, P.K.; Singh, B.K. Chicken eggshell powder as dietary calcium source in chocolate cakes. The Pharma Innovation 6, 1-4(2017).

22) Annisa, R.; Angkasa, D.; Yanti, A.R. Product development of beverages grass jelly (Premna oblongifilia L Merr) with beet (Beta vulgaris) for teenagers. (2017).

23) Cardoz, M.R.; Ravikumar, P. Design, development and evaluation of novel oral medicated jellies. Indo Am. J. Pharm. Sci. 4, 1746-1754(2017).

24) Sareen, A.; Gupta, R.C.; Bansal, G.; Singh, V. Comparison of key mineral elements in wild edible fruits of Ziziphus mauritiana and $Z$. nummularia using atomic absorption spectrophotometer (AAS) and flame photometer. Int. J. Fruit Sci. 20 (sup2), S987-S994 (2020).

25) Etiosa, O.R.; Chika, N.B.; Benedicta, A. Mineral and proximate composition of soya bean. Asian J. Chem. Sci. 4, 1-6(2017). 
26) Garrido, J.I.; Lozano, J.E.; Genovese, D.B. Effect of formulation variables on rheology, texture, colour, and acceptability of apple jelly: Modelling and optimization. LWT 62, 325-332 (2015).

27) Ogunleye, M.T.; Bodunde, J.G.; Makinde, E.A.; Sobukola, O.P.; Shobo, B.A. Fertilizer type and harvest maturity index on nutritive content and proximate composition of tomato fruit. Int. J. Veg. Sci. doi.org/10.10 80/19315260.2020.1867688(2021).

28) Ekpete, O.A.; Edori, O.S.; Fubara, E.P. Proximate and mineral composition of some Nigerian fruits. Curr. J. Appl. Sci. Technol. 3, 1447-1454(2013).

29) Zeng, H.; Lazarova, D.L.; Bordonaro, M. Mechanisms linking dietary fiber, gut microbiota and colon cancer prevention. World J. Gastrointest. Oncol. 6, 41 (2014).

30) Kelava Ugarković, N.; Konjačić, M.; Malnar, J.; Tomljanović, K.; Šprem, N.; Ugarković, D. Proximate chemical composition, fatty acid profile, and lipid qualitative indices of brown bear meat. Foods 10, 36 (2021).

31) Silva, M.M.; Lidon, F. Food preservatives-An overview on applications and side effects. Emir. J. Food Agric. 28, 366-373 (2016).

32) Shams Najafabadi, N.; Sahari, M.A.; Barzegar, M.; Hamidi Esfahani, Z. Quality characteristics, nutraceutical profile and storage stability of functional beverage prepared from jujube (Ziziphus jujuba var vulgaris) fruit. J. Food Process. Preserv. e15201 (2021).

33) Rani, R.; Dharaiya, C.N.; Singh, B. Importance of not skipping breakfast: A review. Int. J. Food Sci. Technol. 56, 28-38 (2021).

34）Balkanska, R.; Mladenova, E.; And Karadjova, I. Quantification of selected trace and mineral elements in royal jelly from Bulgaria by ICP-OES and ETAAS. $J$. Apic. Sci. 61, 223-232(2017).

35) Hasibuan, A.S.; Shufyani, F.; Rinaldo, R. Determination of mineral Ca content in several kinds of fresh food and processed products as sweetmeat. J. Penel. Farm. Herb. 1, 27-32 (2019).

36) Akalin, A.S.; Unal, G.; Dinkci, N.A.Y.İ.L.; Hayaloglu, A.A. Microstructural, textural, and sensory characteristics of probiotic yogurts fortified with sodium calcium caseinate or whey protein concentrate. J. Dairy Sci. 95, 3617-3628(2012).

37) Rotili, M.C.C.; Villa, F.; Silva, D.F.D.; Rosanelli, S.; Braga, G.C.; Eberling, T. Nutraceutical fruit characterization, nutritional aspects and sensory analysis of dovyalis jams. Cienc. Rural 51, e20200310(2021).

38) Karim, O.R.; Kayode, R.M.O.; Oyeyinka, S.A.; Oyeyinka, A.T. Proximate, mineral and sensory qualities of 'amala' prepared from yam flour fortified with moringa leaf powder. FSQM 12, 10-22 (2013).

CC BY 4.0 (Attribution 4.0 International). This license allows users to share and adapt an article, even commercially, as long as appropriate credit is given. That is, this license lets others copy, distribute, remix, and build upon the Article, even commercially, provided the original source and Authors are credited. 